\title{
A DIGNIDADE HUMANA EM KANT
}

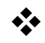 \\ Luana Pagno \\ Universidade Federal de Santa Maria - UFSM - Brasil
}

\section{Resumo}

Kant ao propor uma doutrina do direito, trouxe inúmeras contribuições para o contexto jurídico. Uma dessas contribuições é o conceito de dignidade humana, principal objeto da presente pesquisa, que concerne a ideia de que os seres humanos são fins em si mesmo, e nunca devem ser utilizados como meio para algo. A exposição deste conceito aparece, primeiramente, ligado aos ideais morais kantianos na obra Fundamentação da Metafísica dos Costumes, onde o homem é considerado um ser racional capaz de impor leis a si mesmo e um ser dotado de liberdade, que por isso nunca deve ser utilizado como meio para os outros. Em contrapartida, o mesmo conceito de dignidade aparece em outra obra kantiana, a Metafísica dos Costumes, na qual esse conceito de dignidade é um direito e dever, mas também uma condição para entrar no estado civil. Assim, o objetivo do presente trabalho é estudar o conceito de dignidade humana em Kant a fim de mostrar como ele torna-se importante dentro do contexto do direito, passando a ser não mais uma exigência moral, mas também, um direito e um dever de cada um antes mesmo de entrar na sociedade política. Desta forma, o artigo tem a seguinte metodologia: (1) a análise do conceito de dignidade humana na moralidade; (2) a análise da importância do conceito de dignidade humana no direito em Kant; (3) O surgimento do estado civil e a importância da dignidade, e por fim, a análise de como esse conceito sai da esfera moral e passa a ser relevante na esfera do direito. O estudo é importante porque através dele é possível analisar a importância do conceito de dignidade humana na moral e no direito e as consequências que isso gera para pensar a sociabilização entre moral e direito em Kant.

Palavras chaves: Dignidade; direito; liberdade; valor.

\section{Introdução}

Kant foi um filósofo importante para a noção moderna de direito, devido a diversas contribuições que trouxe ao elaborar uma doutrina do direito em sua obra intitula Metafísica dos Costumes.

Quando Kant descreve os princípios de uma doutrina do direito, o filósofo está muito familiarizado com a tradição anterior e também com o debate político de sua época que se preocupava, principalmente, com a legitimidade política do estado, a justificação da propriedade, os direitos naturais e entre outras coisas, no entanto, além de retomar essas questões, Kant torna-se um filósofo importante por difundir a noção de dignidade humana que vai ser base para desenvolver um estado de direito em sua teoria. 
Essa noção de dignidade humana, que vai ser crucial para desenvolver o conceito de direito e traçar os limites do estado de direito e das leis subjacentes a ele, está muito relacionada com as suas convicções morais, apresentadas novamente nesta obra em que trata do direito, mas, que vem de obras bem anteriores cuja maior referência é a Fundamentação da Metafísica dos Costumes.

O conceito de dignidade, segundo a Fundamentação da Metafísica dos Costumes, está relacionado com uma questão de valor, pois, dignidade para Kant vai ser algo que não tem um preço, algo que não pode ser negociado ou trocado por outra coisa, mas, dignidade é um valor que algo tem em si mesmo.

No reino dos fins tudo tem ou um preço ou uma dignidade. Quando uma coisa tem um preço, pode-se pôr em vez dela qualquer outra como equivalente; mas quando uma coisa está acima de todo o preço, e portanto não permite equivalente, então ela tem dignidade. (KANT, 2011, p.82)

Em decorrência disso, dignidade humana está relacionada com a capacidade do ser humano de não ser um meio para alguma coisa, mas sempre um fim em si mesmo.

Esse conceito de dignidade humana, primeiramente apresentado na moral é retomado no direito enquanto um direito de humanidade que toda a pessoa tem. No entanto, parece ganhar uma conotação política, dado que a dignidade humana se apresenta no âmbito jurídico, tanto como um dever, mas também, como um direito. Um dever que todos têm de respeitar o outro e a si mesmo como pessoas dignas, que são fins em si. E o direito que cada qual tem de exercer essa dignidade no âmbito político.

Dado esses aspectos, o objetivo do trabalho é explorar esse conceito de dignidade dentro da filosofia kantiana, demonstrando como Kant desenvolve uma doutrina do direito baseada nessa noção de dignidade, que aparece na sua moralidade, e como isso é importante para pensar a sociabilidade da moral e do direito, um problema muito debatido pelos estudiosos kantianos.

Assim, o texto será composto por algumas etapas: (1) primeiramente, consta uma breve apresentação do conceito de dignidade colocando em ênfase os conceitos de liberdade e autonomia; (2) seguidamente, apresenta um estudo de como esse conceito encontra-se engajado no âmbito da moralidade. (3) A seguir o artigo visa mostrar como o direito se desenvolve baseado nesse conceito de dignidade e como atribui novos complementos e papéis a esse conceito, papéis estes que são essenciais para o desenvolvimento do estado civil. E, por último, apresenta-se uma pequena conclusão de como o conceito de dignidade passa a ser 
relevante não apenas na moral, mas também no direito e como isso conduz para um problema de sociabilidade entre moral e direito na filosofia kantiana.

\section{O que é dignidade humana?}

A palavra dignidade, em seu sentido usual, está relacionada com respeito, honestidade e entre outras coisas, que tem um parecer mais moral. No entanto, é interessante notar que Kant expõe esse conceito relacionando ao sentido de valor, que embora não deixa de ter uma conotação moral, traz uma ideia interessante de que dignidade é algo que não tem um preço.

O termo dignidade faz referência a algo que não para ser trocado por outra coisa de valor equivalente, mas, é algo que possui um valor intrínseco.

\footnotetext{
No reino dos fins tudo tem ou um preço ou uma dignidade. Quando uma coisa tem um preço, pode-se pôr em vez dela qualquer outra como equivalente; mas quando uma coisa está acima de todo o preço, e portanto não permite equivalente, então ela tem dignidade. (KANT, 2011, p.82)
}

Neste sentido, Kant institui que dignidade não faz referência só ao sentimento de respeito pelo próximo, nem de honestidade com os outros, mas, do valor que esse ato possuiu em relação às pessoas envolvidas nele. Assim, demanda pensar não só no ato de respeitar ou de ser honesto, mas, é pensar no que há por trás desse ato, ou seja, qual é o valor que o determina e, acima de tudo, como esse valor concerne às pessoas.

Essa ideia de dignidade é importante, pois, a dignidade humana, a luz da perspectiva kantiana, não é simplesmente falar de comportamento dos homens, mas, falar do valor essencial que cada ser humano carrega em si que não permite que ele seja tratado como algo que possuí um preço, algo que pode ser usado como meio, mas, sempre na ideia de que o ser humano é um fim em si mesmo.

Essa ideia de que o ser humano é um fim em si mesmo, é desenvolvida por Kant, primeiramente em suas obras sobre morais, como a Crítica da Razão Prática e a Fundamentação da Metafísica dos Costumes (1785), sendo assim, é necessário compreender o conceito de dignidade humana, primeiro através no âmbito moral.

\section{A dignidade humana na moral kantiana}

A moral kantiana é desenvolvida por Kant três pretensões básicas: a ideia de elaborar uma moral universal; a ideia de elaborar uma moral que não é imposta por uma autoridade 
exterior, mas, pelo próprio ser humano; e a ideia de que agir moralmente não está relacionado com motivações egoístas ou interesses pessoais.

A ideia de elaborar uma moral universal está relaciona com a crítica que Kant faz aos seus antecessores que tentaram elaborar uma moral pautada nos sentimentos, ou na experiência, ao invés de propor uma moral universal.

Essa ideia kantiana de universalidade está relacionada com a crença de que uma teoria moral deve valer para todos os seres humanos, e não deve ser algo contingente, mas, necessário. Desta forma, segundo ele a moral também não deve ser fundada na experiência que nunca fornece a universalidade das coisas, mas apenas na razão humana.

\begin{abstract}
Princípios empíricos nunca servem para sobre eles fundar leis morais. Pois a universalidade com que elas deve valer para todos os seres racionais sem distinção. A necessidade prática incondicional que por isso lhes é imposta desaparece quando o fundamento dela se deriva da particular constituição da natureza humana ou das circunstancias contingentes em que ela está colocada. (KANT, 2011, p.92)
\end{abstract}

Assim, a outra característica da moral, a ideia de que a moralidade não deve ser imposta por uma autoridade exterior, faz parte da sua própria concepção de ser humano, cujo principal atributo é a liberdade. Para Kant pelo fato de o ser humano ser racional e possuir liberdade, ele possui a capacidade de escolher livremente, isto é, tomar decisões pautadas na razão e não naquilo que a sua parte sensível impõe. "A todo o ser racional que tem uma vontade temos que atribuir-lhe necessariamente também a ideia da liberdade, sob a qual ele unicamente pode agir" (KANT, 2011, p.99)

Neste sentido, para Kant o homem é único ser capaz de produzir uma vontade livre, capaz de escolher independente daquilo que os seus sentimentos ou seus interesses pessoais demandam. Kant chama de vontade livre uma boa vontade, na medida em que, é uma vontade boa em si, e não boa pelo fim que realiza, ou seja, não boa por que torna o homem feliz ou satisfeito, mas, é boa em si mesma.

\begin{abstract}
A boa vontade não é boa por aquilo que promove ou realiza, pela aptidão para alcançar qualquer finalidade proposta, mas tão somente pelo querer, isto é, em si mesma, e, considerada em si mesma, deve ser avaliada em grau muito mais alto do que tudo o que por seu intermédio possa ser alcançado em proveito de qualquer inclinação, ou mesmo, se quiser, da soma de todas as inclinações. (KANT, p.23, 2011)
\end{abstract}

Para Kant o homem, como racional e livre, tem condições de agir por autonomia, ao invés de heteronomia, isto é, de impor leis para sua própria vontade, independente da determinação da sensibilidade. "Autonomia da vontade é aquela sua propriedade graças a qual 
ela é para si mesma a sua lei (independente da natureza dos objetos do querer)" (KANT, 2011, p. 90)

Essa concepção kantiana de homem, cujas propriedades é ser racional e possuir uma faculdade de liberdade, também está relacionada com a capacidade inteligível dos homens.

$\mathrm{Na}$ natureza, segundo o filósofo, uma coisa determina a outra, isto é, na natureza as coisas ocorrem pela lógica causa e efeito. O homem, em contrapartida, por possuir essas faculdades, é um ser que embora esteja em contato com a natureza e tenha sua parte sensível, não têm a mesma causalidade dela, na medida em que, á capaz de iniciar por si próprio uma série de fenômenos, sendo indeterminado.

Assim, como ser indeterminado, o homem para Kant não faz parte apenas do âmbito sensível, mas, do inteligível e por isso é livre de toda a causalidade da natureza, sendo que, pode impor leis a si mesmo.

\footnotetext{
Por tudo isto é que um ser racional deve considerar-ser a si mesmo como inteligência (portanto não pelo lado das suas forças inferiores), não como pertencendo ao mundo sensível, mas como pertencendo ao mundo inteligível; tem por conseguinte dois pontos de vista dos quais pode considerar-se a si mesmo e reconhecer leis do uso das suas forças, e portanto de todas as suas ações: o primeiro; o segundo, como pertencendo ao mundo inteligível, sob leis que, independentes da natureza, não são empíricas, mas fundadas somente na razão. (KANT, 2011, p.109)
}

Por essas razões, a moralidade para Kant não é algo imposto de fora do ser humano por uma autoridade exterior, mas, pelo próprio ser humano. Além disso, a ação moralmente correta para Kant nunca é aquela que tende a atender alguma demanda da sensibilidade, como os interesses e os sentimentos, mas sempre está relacionada com a escolha determinada unicamente por respeito às leis da razão.

É dentro deste contexto que o conceito de dignidade é inserido. Como visto até agora, Kant desenvolve uma moral pautada principalmente na ideia de que o homem, por ser racional, possui a faculdade de liberdade, e, portanto, pode agir e se governar livre das demandas da sensibilidade, ou seja, pode agir de maneira incondicionada.

Agir de maneira incondicionada significa não agir com a condição de alcançar algo, mas, unicamente por que isso é um dever. Desta forma, agir de maneira incondicionada e livre é agir não por aquilo que a sensibilidade, os sentimentos e os interesses pessoais querem, dado que neste caso existe uma condição para realizar a ação. Mas, é agir unicamente pela razão. 
Por exemplo, quando uma pessoa ajuda alguém para parecer bom diante dos outros, ela está agindo com a condição imposta por um sentimento que é "age bem se quiser conquistar a fama de boa pessoa", ou seja, o "se" representa que a ação está condicionada.

O que é importante do ponto de vista da dignidade, a qual se encontra relacionada com esse parecer da moralidade kantiana, é que numa ação deste gênero a pessoa que será ajudada está sendo utilizada como um meio para algo, e não como um fim. E de forma análoga, a própria pessoa que escolhe agir desta maneira, ou seja, aquela que ajudou outrem condicionada pelo interesse da inclinação, também faz de si mesmo um meio e não um fỉm, dado que realiza o que a sua sensibilidade requer.

Pois bem, para Kant, a dignidade se assenta justamente nessa ideia. Pois, como demonstrado acima, dignidade é algo que possui um valor em si, ou seja, algo que não tem um preço. Assim, a dignidade do homem em Kant concerne a ideia de que ele é um fim em si mesmo e não um meio. Ou seja, ele não pode ser a condição para algo por que possui faculdade de liberdade e razão.

Assim, tal como o agir, para ser moral, não pode ser condicionado pela sensibilidade, da mesma forma o homem, como ser dotado de faculdade de liberdade e de razão, também é incondicionado, no sentido acima explicitado, e nunca deve ser meio para algum fim.

Nesse sentido, é possível ver que a noção de dignidade humana é muito relevante para o agir moral. Pois, dado que agir moral é agir unicamente por dever, isto é, por necessidade de respeitar a lei e não por necessidades patológicas, esse agir pressupõe dignidade no próprio ser humano.

E dado que as pessoas precisam reconhecer umas às outras como dignas, a dignidade também aparece como um dever que será expresso pelo imperativo categórico. Imperativos são comandos objetivos da razão para as máximas das ações, e são categóricos porque obrigam de maneira incondicionada, isto é, exigem que o comando seja obedecido sem outro fim, se não a obediência a lei. "O imperativo categórico seria aquele que nos representasse uma ação como objetivamente necessária por si mesma, sem relação com qualquer outra finalidade." (KANT, 2011, p. 52)

As máximas das ações são princípios subjetivos da ação, ou seja, são princípios que vem antes da realização das ações onde estão contidas as pretensões do agir, por exemplo, como vou agir e porque acho que devo agir assim. Nesse sentido, as leis morais, na forma de 
imperativos categóricos, devem gerir comandos objetivos para essas máximas sem considerar seu fim, mas, apenas a sua forma, com vista a torna-las objetivas e universais.

O imperativo categórico, segundo Kant, tem várias formulações, a partir dos quais, através da máxima, uma ação pode ser considerada correta ou não, uma delas, que expressa a noção de dignidade humana, se apresenta da seguinte forma: "Age de tal maneira que uses a humanidade, tanto na tua pessoa como na pessoa de qualquer outro, sempre e simultaneamente como fim e nunca simplesmente como meio" (KANT, 2011, p.73)

Vê-se que nessa formulação do imperativo categórico, a lei auto imposta pela razão, livre da sensibilidade, exige que ação seja realizada considerando a si como digno e aos outros também. Ou seja, a dignidade humana na moral é uma exigência da moral, mas, é também um pressuposto para agir moralmente.

No direito ela é considerada a luz desse mesmo conceito, porém não apenas sujeita a moralidade, mas sujeita a condição humana e as relações humanas.

\section{O conceito de dignidade no direito}

Como se mostrou acima, o conceito de dignidade pode ser resumido pela ideia de que o homem é sempre um fim em si e nunca um meio. Quando ele aparece nas obras morais kantianas, o filósofo procura associá-lo com a ideia de que o ser humano é um ser racional com condições para exercer a autonomia da sua vontade, por isso, tem dignidade. No direito esse conceito é retomado, mas recebe, além disso, uma conotação política capaz de legitimar o estado de direito.

Para se ter ideia o conceito de dignidade aparece na obra Metafísica dos Costumes quando Kant retoma aquelas fórmulas da divisão dos deveres de direito propostas pelo jurista romano Ulpiano. As formas são três: honeste vive (seja um ser humano honesto); neminem laede (não prejudica ninguém) e suum cuique tribue (se não pode deixar de se associar com os demais, participa de uma associação onde cada um receba o que é seu).

A fórmula mais importante para o artigo é a primeira, que embora tenha ligação com as demais, é nela que o conceito de dignidade aparece e se mostra com um papel muito importante dentro de uma relação jurídica.

Sejas um ser humano honesto (honeste vive). A honestidade em direito (honestas iuridica) consiste em afirmar a própria dignidade como um ser humano em relação aos outros, um dever expresso pelas palavras: "Não faças de ti mesmo apenas um meio para os outros, mas sejas simultaneamente um fim para eles.” (KANT, 2003, p.82) 
Honeste vive faz referência a um dever que o ser humano tem diante de si mesmo, na sua relação com os demais, de manter a sua própria dignidade, ou seja, de não se deixar fazer de meio para os outros. E nesse âmbito, assume um papel muito importante, pois, baseado na noção de dignidade humana, vai gerar um dever interno cuja obrigação é oriunda do direito da humanidade na nossa própria pessoa. "Este dever será explicado mais tarde como obrigação oriunda do direito de humanidade em nossa própria pessoa (KANT, 2003, p.82)

O direito de humanidade na nossa própria pessoa nada mais é do que a liberdade, tanto que é apresentado por Kant como um direito inato. Porém, a liberdade nesse contexto tem um papel diferente daquele em que se apresentou na moral, pois, é a independência de ser constrangido pela escolha a alheia. "A liberdade (a independência de ser constrangido pela escolha alheia) na medida em pode coexistir com a liberdade de todos os outros de acordo com a lei universal, é o único direito original pertencente a todos os homens de acordo com a humanidade destes" (KANT, 2003, p. 83)

A liberdade enquanto direito inato, difere-se de um direito adquirido, isto significa que antes mesmo de adentrar no estado de direito este direito já pertence a cada ser humano.

Sendo assim, a formula honeste vive impõe o dever de cada ser humano de preservar a sua dignidade e tem a sua origem na liberdade. Desta forma, dignidade é uma obrigação que nos mesmos devemos preservar antes de entrar no estado de direito já que origina-se em um direito inato que pertence a cada um de nós.

Por ser algo que cada ser humano deve obrigar a si, ou seja, cada ser humano não deve fazer de si um meio para outros, honeste vive trata-se de um dever interno. Pois, não é uma exigência da lei externa, mas é uma exigência que nós mesmos devemos auto impor a nós. Como demonstra Pinzani (2009, p.99) relaciona-se com a proibição da auto escravidão.

\footnotetext{
A honestidade jurídica não consiste, portanto, em primeiro lugar, no cumprimento da lei (nós nos encontramos ainda em um estado pré-jurídico, como Kant mesmo acentua duas linhas à frente), mas na afirmação de seu valor como ser humano em relação aos outros. É uma atitude interna que antecede a existência de normas jurídicas e, portanto, do direito em geral. O preceito do "honeste vive" tem em vista, em primeiro lugar, a proteção da liberdade externa frente à autoabnegação. Ele serve à proteção "interna" desta liberdade, enquanto o direito serve à proteção "externa", a proteção contra possíveis violações alheias. Esta primeira regra representa por isso, antes de tudo, uma proibição, a saber, a proibição da auto-escravidão.
}

Dentro desse contexto não é algo que precisa necessariamente ser imposto no contexto jurídico, mas antes mesmo de entrar nele. Isto é, quando Kant apresenta o conceito de 
dignidade no âmbito jurídico não o vê apenas como exigência do estado de direito, mas como exigência para entrar no estado de direito, que começa como um dever do próprio indivíduo diante dele mesmo.

Para que isso fique mais claro é necessário retomar a ideia da entrada no contexto de direito.

\section{O surgimento do estado civil e a dignidade humana}

Kant faz todo um trajeto na obra Metafísica dos Costumes, para chegar a apresentar a necessidade do estado civil. O trajeto traçado por ele, assim como fizeram muitos filósofos da modernidade, gira em torno da questão da propriedade.

A diferença audaciosa que Kant revela em relação aos filósofos anteriores a ele, é que as relações de posse, para se tornarem propriedades legitimas, dependem da inteligibilidade do ser humano, isto é, de sua capacidade de postular leis, independente da experiência, a partir da sua razão e da sua liberdade. Isso é visível quando Kant nos apresenta a necessidade do conceito de posse inteligível, em oposição a posse empírica, como o conceito primordial para assegurar a posse definitiva. Além disso, isto também é visível a partir da ideia kantiana de que a razão pensa uma comunidade original de terra, a partir da qual pensa em sentido as relações de propriedade são coerentes.

Portanto, para entender como constitui-se a sociedade civil, e como as leis jurídicas são institucionalizadas de modo justo, na perspectiva kantiana, não é possível ignorar esses conceitos. Entretanto, dado que isto merece um trabalho mais árduo, o presente artigo irá tratar apenas, de modo resumido, da importância do conceito de comunidade original para chegar a criação do estado civil e sua relação com a dignidade.

A comunidade original de terra, segundo Kant, não é um acontecimento histórico, mas, é um conceito imaginário e não empírico, semelhante a ideia de um estado de natureza, propostos por muitos filósofos modernos. Esse conceito tende a afirmar que todos os homens estão de posse legitima de terra, pelo fato de que a natureza os colocou em um determinado lugar sem que eles tivessem vontade sobre isso. Por essas razões tal posse originária, e é diferente da residência, por que a primeira não é voluntária como a segunda, que parte de um ato de vontade. Como mostra Kant no seguinte trecho da obra:

Todos os homens estão originariamente (ou seja, antes de todo ato jurídico do arbítrio) na posse legítima do solo, isto é, eles têm direito a estar ali onde a natureza ou o acaso os colocou (sem sua vontade) Essa posse, que diferente da residência, 
enquanto posse voluntária e duradoura, portanto adquirida, é uma posse comum por causa da unidade de todos os lugares sobre a superfície da terra como superfície esférica. Pois, se ela fosse um plano infinito, os homens nunca poderiam dispersarse tanto que não entrariam em nenhuma comunidade uns com os outros, esta não sendo, portanto, uma consequência necessária de sua existência sobre a terra. - a posse de todos os homens sobre a terra, que precede todo ato jurídico dos mesmos (e é constituída pela natureza mesma, é uma posse comum originária cujo conceito não é empírico nem depende das condições temporais - como, por exemplo, o conceito, imaginário e indemonstrável de uma posse comum primitiva. Ele é um conceito prático da razão, que contém a priori o único princípio segundo qual os homens podem fazer uso, segundo leis jurídicas, do lugar que ocupam na terra. (KANT, 2013, 262, P, 68)

Dado que a ideia de comunidade original não é um fato, Kant procura mostrar que ela é um conceito prático da razão, conceito este que afirma que todos os homens nascem com uma posse originária que, por causa da limitação da terra e por não ser um ato de vontade, é uma posse que não é jurídica, nem efetiva.

Dentro deste contexto, qualquer aquisição de terra, isto é, qualquer ato empírico e voluntário de apoderamento de terra, por exemplo, implica numa situação judicial, pelo fato de que um quando um indivíduo toma posse de algo que é de todos, cria uma situação paradoxal, de inibição de liberdade, isto é, cria uma relação de obrigação, dado que esse ato implica a proibição ou a privação da liberdade de outrem de fazer uso desse espaço. "Se declaro (verbalmente ou por meio de atos) pretender que algo exterior seja meu, então declaro a todos como obrigatório abster-se do objeto de meu arbítrio: uma obrigatoriedade que ninguém teria sem esse meu ato jurídico.” (KANT, 2013, p. 61)

Dentro deste contexto, Kant impõe a necessidade de que a posse torne-se propriedade, isto é, seja efetiva, somente mediante um consentimento comum. Pois, a vontade de um só não serve para impor uma coerção a todos, justamente pela contingência a qual está sujeita. Portanto, somente uma vontade universal, ou comum é capaz de definir a posse.

Essa vontade comum, em contrapartida, nada mais é do que o estado civil. Assim, Kant, diferente de alguns filósofos anteriores a ele, e mesmo assim, um pouco semelhante a Rousseau, estabelece a ideia de uma vontade comum como pilar para o estado civil. Que é explicada por Kant a partir dessa ideia de necessidade de regulamentação da propriedade.

Portanto, somente uma vontade que obriga a cada um qual é que é, por conseguinte, coletivamente universal (comum) e detentora de poder, pode oferecer a cada um aquela segurança. Mas o estado submetido a uma legislação externa universal (isto é, publica) acompanhada de poder é o estado civil. Somente no estado civil, pois, podem existir um meu e um seu exteriores. (KANT, 2003, p. 61) 
O aspecto interessante, é que está ideia de vontade comum, envolve algo muito importante para pensar o papel da dignidade humana. A vontade comum, representa a vontade de todos os cidadãos unidas. Isto significa que não há soberano responsável pelo estado civil que obriga a todos de acordo com a sua vontade, mas, é a vontade de um unificado com a vontade de todos os outros.

Isso significa que ser humano, na percepção kantiana, não deve entrar no estado civil coagido por outro, mas pela sua própria vontade. Isto revela a ideia acima apontada da dignidade humana antes mesmo do estado civil, pois, a ideia aqui é que o ser humano não faça um contrato como meio para atingir a finalidade de outrem, mas, motivado pela sua própria finalidade.

E não se pode dizer que o homem no estado sacrificado a um fim ma parte de sua liberdade externa inata, mas sim que teria abandonado por completo a liberdade selvagem e sem lei para, numa situação de dependência legal, isto é, num estado jurídico, reencontrar intacta sua liberdade em geral, pois essa dependência surge de sua própria vontade legisladora. (KANT, 2013, P.122)

Nesse trecho da Metafísica dos Costumes Kant esboça um pouco essa ideia mediante o conceito de liberdade. Nesse trecho ele afirma que o homem não é sacrificado, ou seja, obrigado por um fim de alguém a abrir mão de sua liberdade, mas, entra em uma dependência de leis, isto é, no estado civil, e continua livre porque essa dependência provém da sua própria vontade legisladora. Isto é, o homem mesmo obriga a si a entrar no estado civil através de um ato de vontade, e isso significa que ele mesmo impõe um fim a si, ao invés de fazer de si um meio para a vontade de outro.

\section{Considerações finais}

O tratamento do conceito de dignidade humana, no contexto da moralidade kantiana, conduz a ideia de que dignidade é, por um lado, algo que o próprio indivíduo reconhece em si, pelo fato de ser racional e livre, mas, por outro lado, também trata-se de uma exigência do imperativo moral para com os outros e para consigo mesmo.

O conceito de dignidade humana, nesta perspectiva é um pressuposto para moral, por que apenas reconhecendo-se como um fim em si e não como o meio para atingir o fim da inclinação, o ser humano encontra-se possibilidade para promover ações que tem valor moral. Em contrapartida, esse mesmo conceito também torna-se uma exigência da moralidade, isto é, é um mandamento do imperativo tratar a si e aos outros como dignos. 
Dentro deste contexto, o conceito de dignidade, pautado na ideia de que o ser humano é um fim em si mesmo e não deve ser tratado como meio, vem assegurando mediante um ato auto coercitivo, isto é, uma autoimposição em que o ser humano coage a si mesmo a tratar a si e aos outros como dignos e a reconhecer-se como tal.

De forma análoga a moral, o conceito de dignidade aparece no âmbito do direito, no entanto, ganha uma importância extrema nessa abordagem, porque é primordial para criar uma condição civil que evite o monarquismo absoluto, a própria escravidão e entre outras coisas deste mesmo cunho.

O conceito de dignidade humana, no contexto de direito, é enriquecido com outros atributos e papéis que são fundamentais para pensar o estado civil kantiano como um estado republicado, e para pensar o papel do indivíduo moral nessa tarefa. Primeiramente atribui-se ao conceito de dignidade a ideia de que é um direito e um dever de todos, não só para com os outros, mas, para consigo mesmo, que é baseado em um direito inato: a liberdade. Posteriormente recebe o papel de proibir a auto escravidão, isto é, mostra a necessidade de cada um, antes mesmo de entrar na sociedade civil, ser digno de si mesmo.

Dado que o conceito de dignidade humano é tanto pressuposto para moral, como também, exigência dela, ao aparecer no direito como algo baseado em um direito inato que, além disso, é um dever que todos têm para consigo antes de entrar no estado civil, vê-se que existe uma tentativa, ainda que pouco elaborada, de aproximar a moral e o direito em Kant. Pois, na medida em que o ser humano precisa reconhecer-se como digno para entrar no estado de direito, e na medida em que a dignidade é um pressuposto para a moral e uma exigência dela, é possível notar que o direito em Kant, e a formação do estado civil é constituída a partir da compreensão do ser humano como um ser digno que tende a moralidade.

Em outras palavras, quando Kant insere no contexto político a dignidade como um dever de todos antes de entrar no estado civil, acatando a ideia de uma vontade legisladora, unida com a vontade dos demais, como um pressuposto para evitar a auto escravidão e a monarquia absoluta, busca reforçar a ideia de que no estado civil deve-se evitar que as pessoas tornam-se meios para atingir a vontade de um só. Mas também, ao considerar que o indivíduo possui dignidade antes mesmo de entrar no estado civil, Kant parece reforçar a ideia de que este deve ser um espaço aberto onde tanto a dignidade, e juntamente com ela a moralidade (dado que a primeira é um pressuposto para a segunda, mas, ao mesmo tempo é uma exigência da dela), possa ser realizada. 
Isto resulta que o conceito de dignidade, apesar de não ser modificado em ambos os contextos, permeia uma conexão entre a moral e o direito, pois, é a base para assegurar a justiça e a possibilidade de liberdade e da moral no estado civil.

\title{
THE HUMAN DIGNITY IN KANT
}

\begin{abstract}
Kant to propose a doctrine of law, brought numerous contributions to the legal context. One of these contributions is the concept of human dignity, the main object of this research, which concerns the idea that human beings are ends in themselves, and should never be used as a means to something. The exhibition of this concept appears, first, on the Kantian moral ideals in the Customs Metaphysical Reasoning work, where the man is considered a rational being able to enforce laws himself and a being endowed with freedom, which therefore should never be used as a means for others. In contrast, the same concept of dignity appears in another Kantian work, the Metaphysics of Morals, in which the concept of dignity is a right and duty, but also a condition to enter the marital status. The objective of this work is to study the concept of human dignity in Kant in order to show how it becomes important within the right context, becoming no longer a moral obligation but also a right and a duty to each before entering the political society. Thus, the article has the following methodology: (1) the analysis of the concept of human dignity in morality; (2) the analysis of the importance of the concept of human dignity in law in Kant; (3) The emergence of civil status and the importance of dignity, and finally the analysis of how this concept out of the moral sphere and becomes relevant in the sphere of law. The study is important because through it is possible to analyze the importance of the concept of human dignity in the moral and the law and the consequences it generates to think socialization between morality and law in Kant.
\end{abstract}

Key words: Dignity; right; freedom; value.

\section{Referências}

ABBAGNANO, N. Dicionário de Filosofia. São Paulo: Martins Fontes, 1998.

ALAMAYO, R. Immanuel Kant: La utopía da moral como emancipación Del azar. Madrid: EDAF ensayo, 2001.

ALLISON, H. E. Kant's theory of freedom. Cambridge: Cambridge University press, 1990.

ARENDT, H. Conferencias sobre la filosofía política de Kant. Buenos Aires: Paidós, 2003. 
BECKENKAMP, J. “O direito como exterioridade da legislação prática em Kant”. In: Revista Ethica, v. 2, n. 2, p. 151-171, 2003.

BOBBIO, N. Direito e Estado no pensamento de Emanuel Kant. São Paulo: Mandarim, 2000 .

BOBBIO, N. BOVERO, Michelangelo. Sociedad y Estado em la filosofia política

moderna. México: Fondo de Cultura econômica, 1986.

BOBBIO, Norberto; MATTEUCCI, Nicola; PASQUINO, Gianfranco. Dicionário de

Política. Brasília: Editora Universidade de Brasília, 1998.

DELEUZE, G. A filosofia Crítica de Kant. Lisboa: Edições 70, 2000.

GALEFFI, R. A filosofia de Immanuel Kant. Brasília: Editora Universidade de Brasília, 1986.

GUYER, P. Kant. Aparecida, São Paulo: Editora Ideias e Letras, 2009.

HECK, J. N. "Direito racional e filosofia política em Kant". In: Tempo da Ciência, Cascavel, v. 11, n. 22, p. 57-80, 2004.

HÖFFE, O. Immanuel Kant. São Paulo: Martins Fontes editora, 2005.

. “O imperativo categórico do direito”. In: Studia Kantiana, v. 1, n. 1, p. 203-236, 1998.

KANT, I. A fundamentação da Metafísica dos Costumes. Lisboa, Portugal: Edições 70, 2011.

A Metafísica dos Costumes. São Paulo: Editora Universitária São Franscisco,

2013

A Metafísica dos Costumes. São Paulo: Editora Edipro, 2003.

. Crítica da Razão Prática. São Paulo: Martins Fontes editora, 2002.

.Crítica da Razão Pura. Lisboa: Fundação Calouste Gulbenkian, 2013.

NOUR, Soraya. “O legado de Kant à filosofia do Direito”. In: Prisma Jurídico, n. 3, setembro, p. 91-103, 2004.

PASCAL, G. Compreender Kant. Petrópolis: Vozes Editora, 2011.

PERIN, A. O Problema da unidade da Razão em Kant. Uma Reconstrução Sistemática a partir de Três Momentos do Desenvolvimento do Período Crítico. Porto Alegre: EDIPUCRS, 2008.

PINZANI, Alessandro. Sobre a terceira antinomia. In: KLEIN, Joel Thiago (Org.)

Comentários às obras de Kant: Crítica da Razão Pura. Florianópolis: NEFIPO, 2012. 
. "O papel sistemático das regras pseudo-ulpianas na Doutrina do direito de Kant”. In:

Studia Kantiana, v. 8, pp. 94-119, 2009.

SALGADO, J. C. A ideia de justiça em Kant: seu fundamento na igualdade e liberdade.

Belo Horizonte: Del Rey, 2012.

WOOD, A. Kant. Porto Alegre: Artmed editora, 2008.

ZINGANO, M. A. Razão e historia em Kant. São Paulo, SP: Editora Brasiliense,1989.

OLIVEIRA, M. A. A concepção de ética e direito na filosofia de Kant. In: Síntese. Belo

Horizonte, dez, v. 37, n. 119,2010.

TERRA, R. A política Tensa. São Paulo: editora iluminuras, 1995.

WEBER, Thadeu, HAEBERLIN, Martin P. Equidade na doutrina do direito de kant: um direito que, não sendo um direito, enfraquece a "tese da independência.

Veritas Porto Alegre v. 57 n. 3 set./dez. 2012 p. 121-137

\section{Sobre a autora:}

Luana Pagno é formada em Filosofia pela Universidade Federal da Fronteira Sul. Atualmente, faz mestrado em filosofia na Universidade Federal de Santa Maria. Endereço de e-mail: lp_luana@hotmail.com 